\title{
A IMPORTÂNCIA DA EXTENSÃO UNIVERSITARIA NA FORMAÇÃO DO ENGENHEIRO CIVIL
}

DOI: 10.37702/2175-957X.COBENGE.2021.3672

Vinicius Rafael de Araujo Nogueira - vinicius.enge93@gmail.com UNISAL

Rua Francisco Fadim 520

13140-726 - Paulinia - SP

Aparecida silva Santos carbone - cinda.carbone.pln@gmail.com Unicamp antonio pazetti 632

13140-741 - paulinia - SP

Letícia Peixoto - leh.peixoto@gmail.com

UNISAL

Osvaldo Anhert 550

13034-190 - Campinas - SP

Adriana Aparecida Ambrósio de Souza - adriana.souza@unisal.br unisal

Av. Almeida Garret 267

13087-290 - Campinas - SP

LUCAS NAIF CALURI - Iucasnaifcaluri@gmail.com

Unisal Centro Universitário salesiano de São Paulo

Rua Coelho Neto 331

13023-020 - Campinas - SP

Gabrielle Rohan Maués - gabii.rohan@hotmail.com

Centro Universitário Salesiano de São Paulo

Avenida Papa Pio XII 900

13070-903 - Campinas - SP

Resumo: Em uma perspectiva do atual cenário dos alunos da graduação de engenharia civil ocorre que grande parte dos alunos ingressantes não finalizam o curso ou são desmotivados durante o período da graduação e o presente artigo 
tem como objetivo destacar as atividades de extensão universitária como um meio de despertar interesses e motivação pelo curso através da humanização, educação e sustentabilidade. Quando se trata de sustentabilidade é preciso ter um olhar crítico em todo procedimento desde a concepção do projeto a finalização da construção, analisando as necessidades dos moradores, da localidade do empreendimento, as condições climáticas e muitos outros fatores que influenciam no meio ambiente e no cotidiano do cliente.

Palavras-chave: Comunidades, Extensão Universitária, Humanização, Engenharia 


\section{A IMPORTÂNCIA DA EXTENSÃO UNIVERSITARIA NA FORMAÇÃO DO ENGENHEIRO CIVIL}

\section{INTRODUÇÃO}

A universidade é um espaço que possibilita a agregação de inúmeros saberes heterogêneos. É a base para a formação dos estudantes, para uma carreira profissional e para estender os limites do conhecimento, intensificar a criatividade e moldar a identidade de uma nação.

A graduação é um período de transformações, durante todo processo de aquisição de conhecimento nas universidades, é inevitável não pensar no mercado de trabalho, não se ter ansiedade, e temer o mercado que se torna cada vez mais exigente na contratação dos recém-formados.

Quem persevera até o fim na graduação de engenharia, aspira por uma especialização mais técnica na entrada imediata no mercado de trabalho. No entanto está "motivação", acontece na maioria das vezes nos últimos anos da faculdade, pois é neste momento que se tem acesso as disciplinas especificas do curso. Logo a aquisição deste conhecimento é resultado das práticas constantes laboratoriais e atividades de campo que em conjunto auxiliam na formação do profissional. Enfim ao longo da graduação espera-se ter a construção de um profissional que agregue todas as vivencias e esteja apto as exigências do mercado.

Ao início da graduação torna-se imprescindível "educar" os novos ingressantes para as atividades práticas e posiciona-los como futuros engenheiros, criando assim uma postura profissional. Permitindo assim a este discente o envolvimento com o curso deste do início, possibilitando a este profissional uma formação completa, e por fim reduzindo assim a evasão.

Neste sentido, tem-se que a engenharia se constitui, na atualidade, em uma profissão de aplicação ampla, também multidisciplinar, que possui direcionamento em segmentos. Seja na área de infraestrutura, saneamento, transportes, grandes obras de arte e outras, a engenharia foca-se em resolver problemas e dar soluções, envolvendo planejamento, execução e controle.

A Engenharia é a responsável direta pelos avanços tecnológicos que, cada vez mais proporcionam conforto. Por este motivo, é preciso trazer para a vivência do curso a visão humanística da engenharia civil, permitindo a este profissional a união da teoria, pratica e conhecimento de mundo.

Este engenheiro humanizado resultante destas vivencias terá assim uma formação completa e realista que auxiliará no desenvolvimento de suas atividades após o termino do curso. Basicamente o mercado requer do engenheiro livre iniciativa, proatividade, senso crítico, trabalho em equipe, vontade de inovar e afins, e tudo numa teia de saberes com foco nos clientes e resultados. Segundo Pereira; Bazzo 2006 a engenharia, de uma forma contextualizada tecnológica e humana) encontra-se presente em uma trajetória de inovações e utilidades ao conhecimento.

Desta forma, o setor da construção civil tem contribuído para o desenvolvimento social. Supre necessidades básicas do homem, reduzindo, por exemplo, a lacuna existente entre teoria e prática. O objetivo deste trabalho é avaliar a contribuição da extensão universitária na formação de estudantes do curso de Engenharia Civil da UNISAL/ campus São Jose através da realização de oficinas junto a áreas periféricas da cidade de Campinas/SP. A hipótese inicial é a de que as vivências da extensão e a interação com a 
comunidade externa constituem-se como espaços de formação e de aprendizagem diferenciados e transformação.

\section{PROJETO DE EXTENSÃO UNIVERSITÁRIO}

Historicamente, a extensão universitária transitou por diferentes papeis, desde o assistencialismo, passando pela prestação de serviços, até a difusão dos conhecimentos produzidos na academia junto às comunidades de inserção das universidades (FORPROEX, 2012). Os princípios de uma metodologia ativa estão relacionados com a personalização da aprendizagem, ou seja, fazer com que o aluno seja parte do processo de ensino da maneira com que este se adeque satisfatoriamente (BECK, 2018). Para que ocorra a apropriação do conhecimento é preciso que ocorra a realização de atividades práticas, exercendo a junção do conhecimento e da competência de executar. Segundo Saraiva (2007), a extensão possibilita ao acadêmico a experiência de vivências significativas que lhe proporciona reflexões acerca das grandes questões da atualidade e, com base na experiência e nos conhecimentos produzidos e acumulados, 0 desenvolvimento de uma formação compromissada com as necessidades nacionais, regionais e locais, considerando-se a realidade brasileira.

Portanto, a universidade deve estar inserida permanentemente na comunidade, realizando a troca de experiências, assimilando, revendo valores e prioridades que permitam que a população se identifique como sujeito de sua própria história, proporcionando consequentes mudanças das condições de vidas, superando, assim, problemas sociais encontrados na própria comunidade (LIMA, 2003).

\section{$2.1 \quad 0$ projeto na prática}

O projeto parte da premissa que o ensino de noções técnicas, vinculado à realização de dinâmicas e vivências junto a uma comunidade pode produzir conhecimento, promovendo um aprendizado muito mais consciente e transformador. Inicialmente, é importante salientar que as ações se caracterizam como atividades de educação não formal, ainda que boa parte delas ocorra em espaços institucionalizados como a universidade ou em escolas.

Para a realização deste projeto utiliza-se como ponto fundamental a necessidade de moradia que atenda especificidades técnicas nas comunidades carentes. Tendo como objetivo inicial inserir os discentes nas discussões referentes a planejamento urbano, apresentando a estes a importância de se ter moradia digna que atenda às necessidades básicas das famílias. Contextualizando assim, a importância de uma postura mais humana diante das necessidades e desejos dos futuros moradores, possibilitando a execução de um projeto participativo.

Em contrapartida o discente desde o semestre inicial do curso será estimulado a desenvolver características que permitam a ele uma postura humanizada. Para alcançar este objetivo realizou-se uma atividade junto à comunidade, buscando assim conhecer a realidade e compartilhar o conhecimento adquirido em salas de aula de maneira simples e clara.

\subsection{Oficinas}

A 1aㅡ oficina ocorreu no bairro Vida Nova, na cidade de Campinas, SP. O nome Vida Nova originou-se da missa realizada no local junto com as famílias em que o padre referiu que ali eles teriam uma casa, uma vida nova, e o nome ficou, na expectativa de uma vida 


\section{COBENGE de Educação em Engenharia 2021 de Educaça \\ 28 a 30 de SETEMBRO \\ - Evento Online \\ "Formação em Engenharia: \\ Tecnologia, Inovação e Sustentabilidade"}

melhor. As primeiras atividades foram de aproximações sucessivas da realidade para conhecer a realidade. Estas atividades foram desenvolvidas com o objetivo de promover a formação ética e humanística dos futuros profissionais de engenharia.

No primeiro momento foram apresentadas questões básicas referentes aos processos construtivos, iniciando a discussão através da escolha e uso dos materiais de construção civil, figura 1.

Figura 1 - Apresentação dos requisitos básicas para a construção.
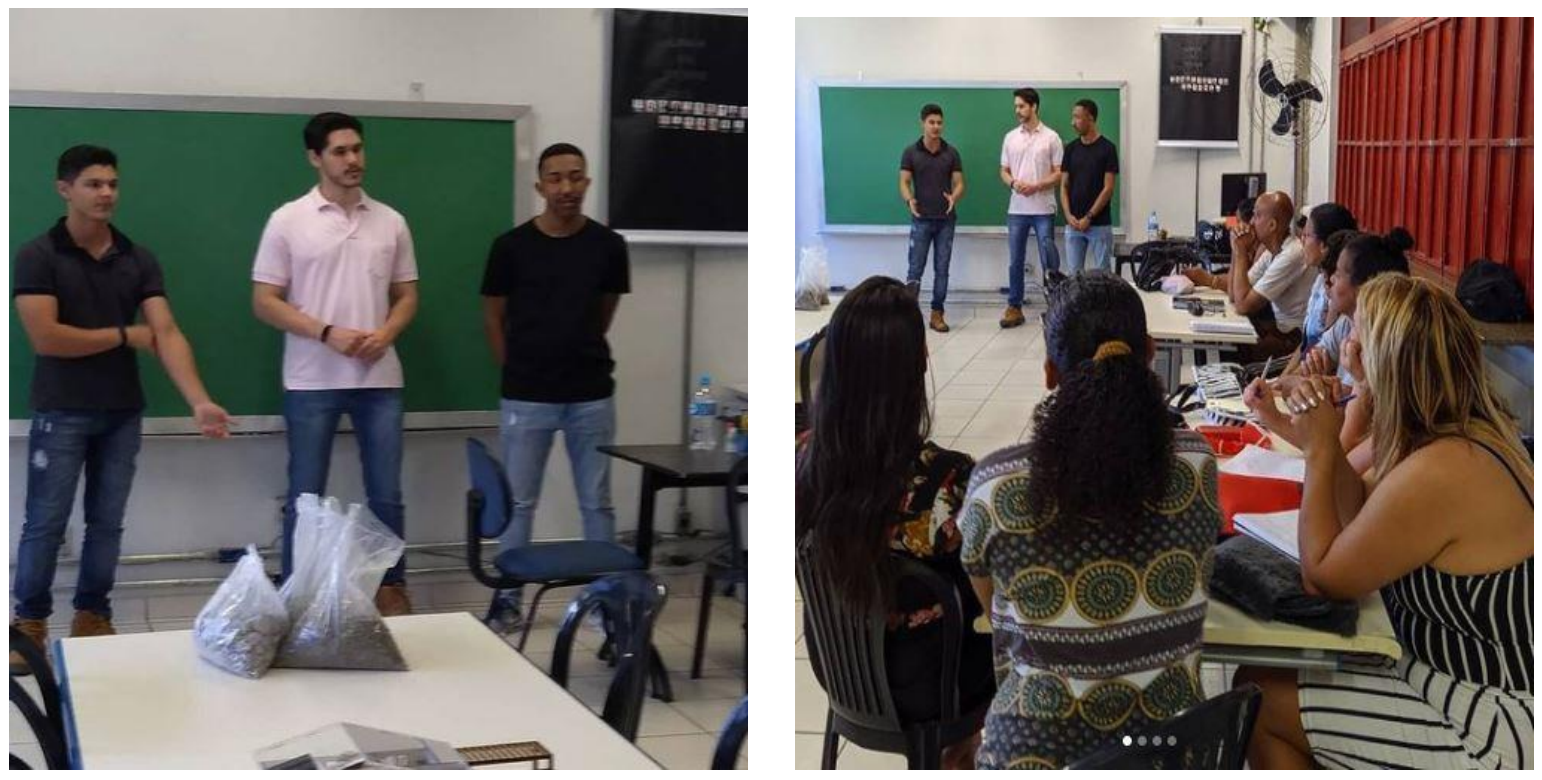

Fonte: Autoria própria.

Observou-se ao realizar essa oficina a participação efetiva do público feminino, sendo este composto de 18 mulheres e um único homem. A grande aderência feminina a esta oficina foi um diferencial, figura 2.

Figura 2 - Efetiva apresentação feminina
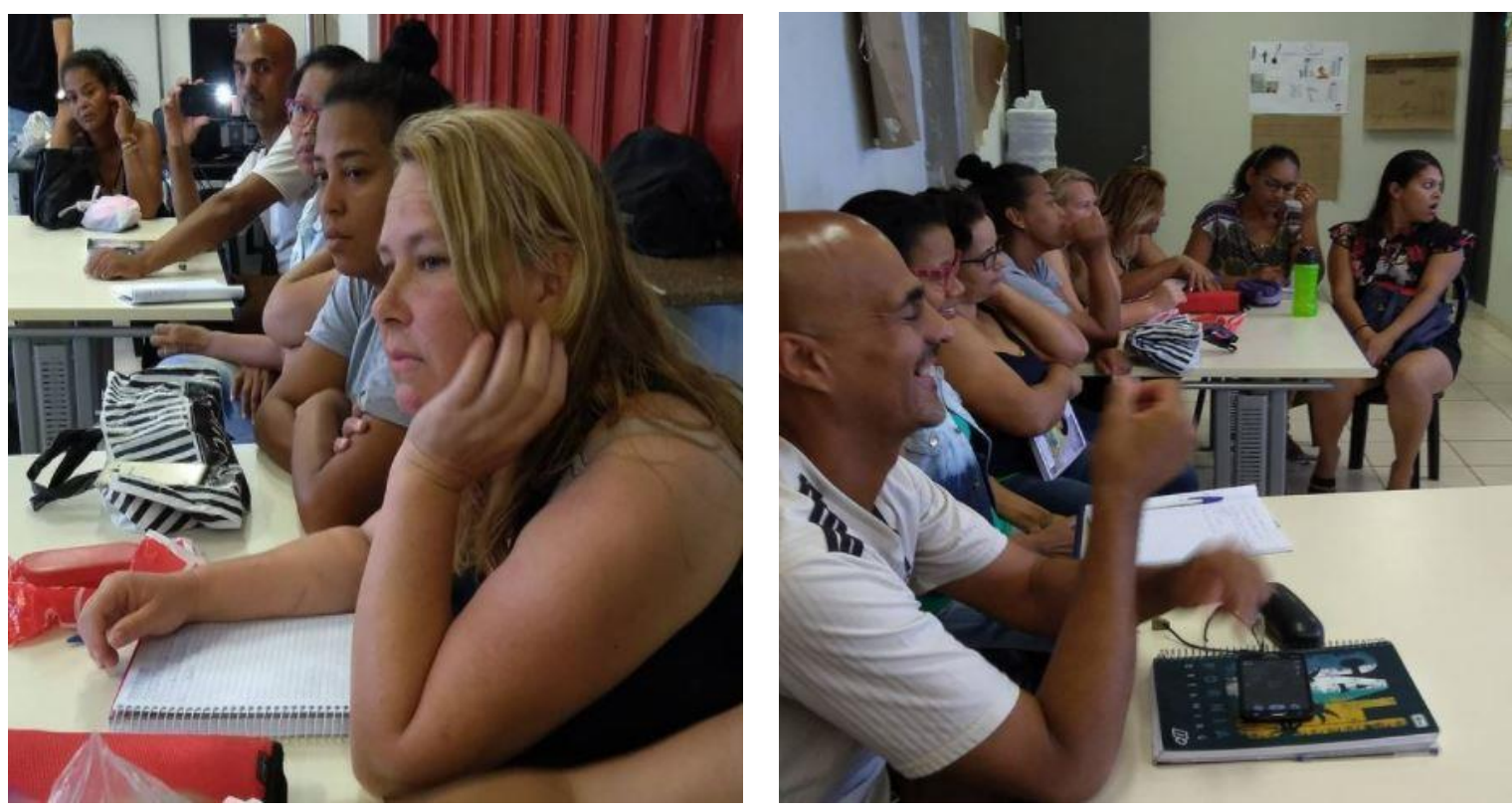
Fonte: Autoria própria.

Pois os temas ali tratados eram característicos de processos construtivos, onde habitualmente observa-se a presença de um público masculino. No entanto, ao questionar as participantes percebeu-se que o seu contexto familiar exigia destas que tomassem a liderança em construir, suas próprias residências, figura 3. Outra perspectiva evidenciada a partir da análise é a integração de experiências de ensino e pesquisa no espaço da extensão universitária, consistente com a premissa de que a indissociabilidade sinaliza um princípio síntese de produção e ressignificação de conhecimentos (PUHL, 2016).

Figura 3 - Participação da comunidade na oficina
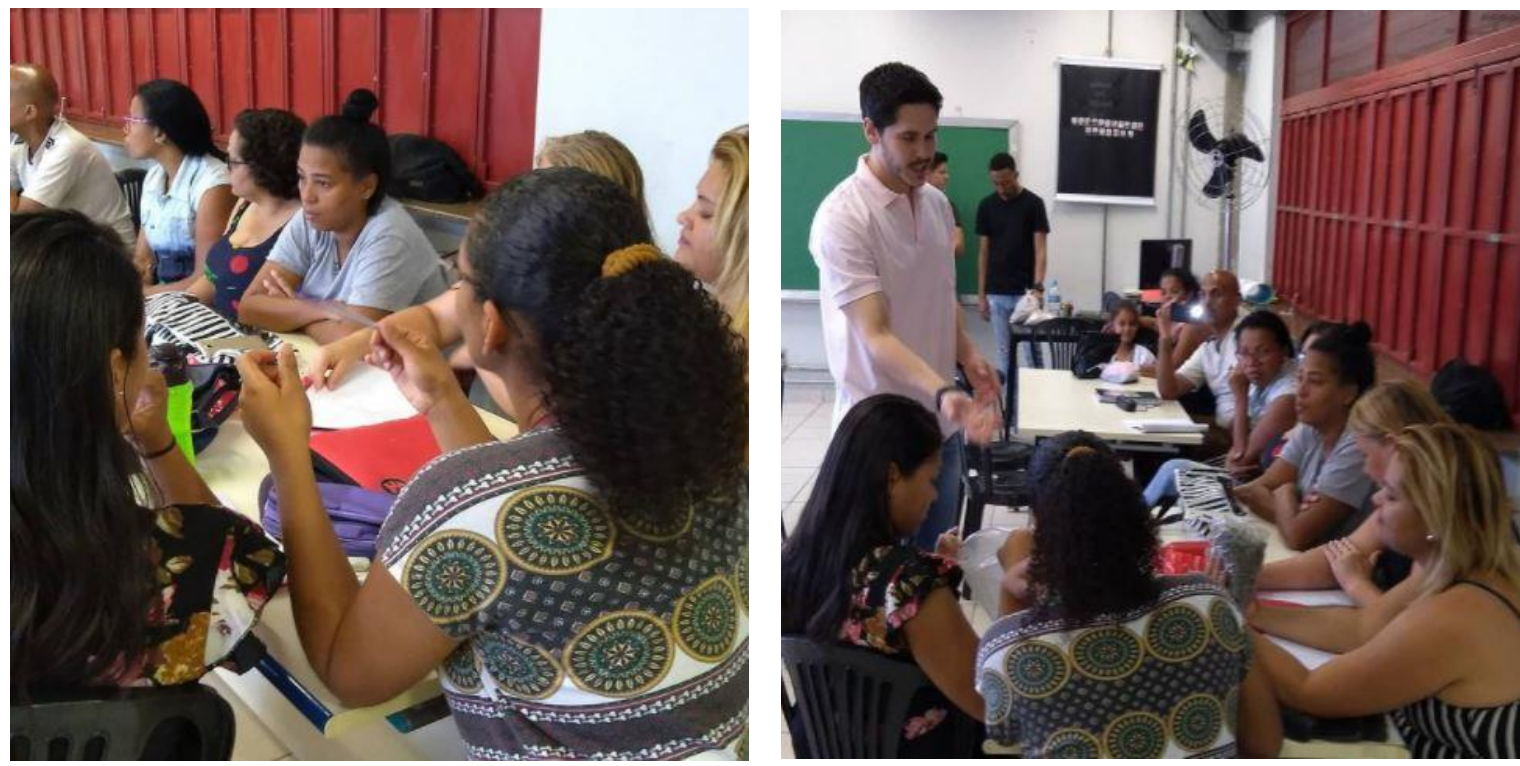

Fonte: Autoria própria.

Cada participante da oficina fora convidado a relatar o processo construtivo realizado em sua moradia. Observou-se que este processo construtivo praticado fora baseado no conhecimento adquirido em rodas de conversas pela comunidade, não havendo parâmetro técnico que garantisse a qualidade do projeto executado. Estes relatos permitiram aos participantes contextualiza as necessidades técnicas para desenvolvimentos dos projetos construtivos futuros, permitindo aos discentes participantes complementar a sua formação em suas múltiplas dimensões colocando em pratica a bagagem teórica adquirida em sala de aula. Figura 4. 
Figura 4 - Participantes e organizadores da oficina.

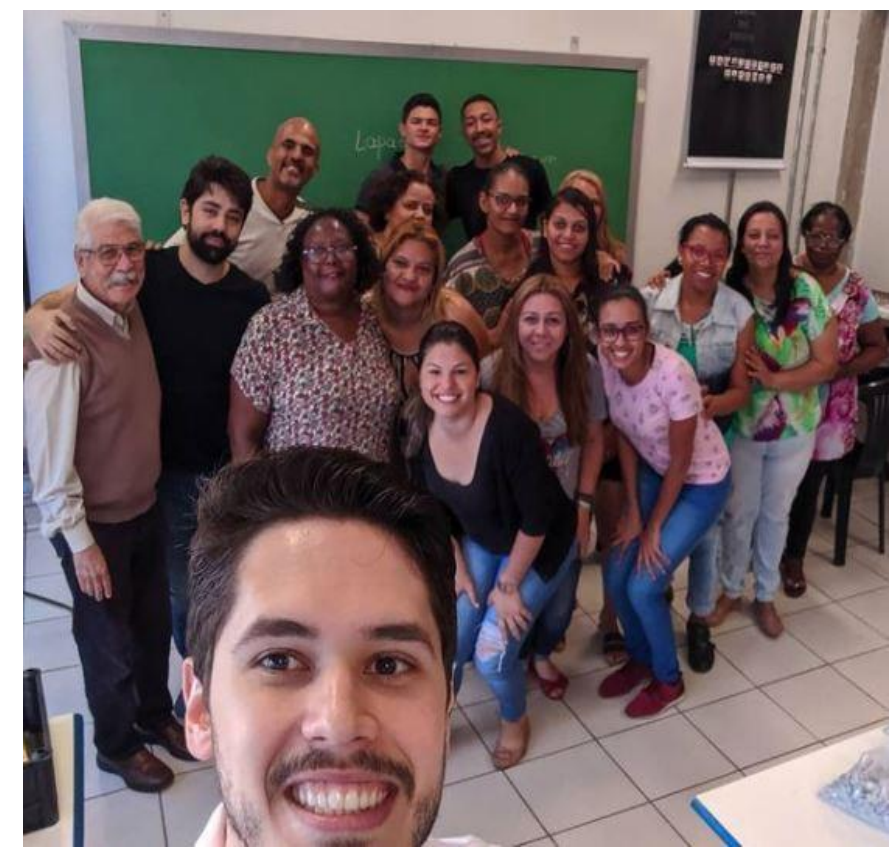

Fonte: Autoria própria.

Logo para estas mulheres participar desta oficina, tem um significado transformador, pois, permitiu o contato conhecimento técnico de maneira clara e acessível. Em contrapartida os discentes participantes, puderam colocar em prática os conhecimentos adquiridos nas aulas de materiais de construção civil, tornando assim este momento de troca em um momento de compartilhamento e construção de vivências. Cabendo a todos os participantes, a compreensão na importância do conhecimento técnico junto ao desenvolvimento de técnicas construtivas.

O desenvolvimento da atividade realizada envolveu a tríplice da engenharia: a humanização, a educação e a sustentabilidade.

- Humanização: é preciso desde cedo nas faculdades ensinar os profissionais a serem mais humanos, passar por processos que faça com que os novos discentes lidem com pessoas. Para entender essa necessidade é preciso sair para o campo e servir a pessoas.

- Educação: a educação sem a humanização não transmite o que precisa ser ensinado. Os alunos ao finalizar a curso, apenas aplicam (ou não) aquilo que aprenderam no mercado de trabalho, no entanto seus ensinamentos ficam guardados. É preciso que nossos conhecimentos sejam ensinados em lugares que as informações não chegam e para que isso ocorra precisamos servir.

- Sustentabilidade: atualmente pensar em sustentabilidade é pensar de um modo geral em comunidade, na economia, no meio ambiente, nos materiais, nos moradores. A sustentabilidade é colocada em grandes empreendimentos, nos prédios, residências, porém ela é esquecida em comunidades de baixa renda, onde eles não conhecem o que é saneamento, reciclagem, cisterna, basta através da humanização e educação.

Esta primeira oficina permitiu criar laços com a comunidade e estimulou os discentes participantes a interagir e construir um espaço de trocas que vão além das atividades realizadas.

O conhecimento produzido a partir deste estudo ainda poderá contribuir com sugestões para o desenvolvimento e ampliação das ações realizadas na universidade em 
parceria com a comunidade, colaborando para que a universidade possa exercer seu papel social e reforçar, em específico, a geração de tecnologias, saberes e inovações que possam estar a serviço da comunidade, reconhecendo-a como sujeito do processo.

\subsection{Implantação das práticas extensionistas}

A implantação de práticas extensionistas nos cursos de engenharia, possibilita maior interação da universidade com a comunidade, proporcionando contato com outras realidades fora do campus proporcionando assim o desenvolvimento social. Estas práticas auxiliarão os discentes no desenvolvimento de características importantes para sua formação:

- Proporcionará ao discente a possibilidade de interagir com a comunidade ao entorno do campus;

- Permitirá a troca de vivências, consolidando o uso da teoria em situações práticas e esclarecedoras do ponto de vista construtivo;

- Valorizar conhecimento de mundo dos participantes, elaborando situações, problemas onde estes será convidado a posicionar-se utilizando o conhecimento adquirido ao longo das atividades desenvolvidas;

Baseando-se nas premissas apresentadas anteriormente, espera-se que este profissional ao vivenciar estas situações problemas, tenha autonomia para a tomada de decisões. Sendo está uma oportunidade de unir teoria, prática e sensibilidade com as questões adversas da comunidade atendida, demonstrando assim que a engenharia deve ser um instrumento de compartilhamento de conhecimento. Permitindo assim uma formação mais humanizada e coerente com as exigências do mercado de trabalho.

\section{Considerações FINAIS}

Trabalho com grupos populares da comunidade devem existir, para que se possa construir uma cultura acadêmica com espaços de integração entre a sociedade e a universidade. Este é apenas o relato inicial deste projeto que será desenvolvido ao longo deste ano, acontecendo de maneira remota devidas restrições da pandemia.

É importante ressaltar que a universidade como um ambiente de formação possui o intuito principal de transmitir e produzir diferentes formas de conhecimento, oferecendo para os alunos uma modalidade que não se restringe a apenas um ensino mecânico e teórico, mas sim um ensino humanizado.

A análise parcial apresentada neste trabalho destaca o potencial da extensão como espaço de transformação de sujeitos - os estudantes universitários, neste estudo de caso mediadores das diferentes atividades desenvolvidas no âmbito de um projeto com foco na divulgação do conhecimento em Engenharia Civil. Demonstrando que o contato com diferentes realidades externas à universidade amplia a visão de mundo e os torna mais sensíveis como seres humanos.

\section{Agradecimentos}

À professora Aparecida S. S. Carbone por todo apoio, que desde o início sempre incentivou, contribuiu e motivou a escrita desse artigo e tornar esse projeto realidade.

\section{REFERÊNCIAS}

ALLEN, E.; THALLON, R. Fundamentals of Residential Construction. Hoboken, NJ: John Wiley \& Sons, 2011. 
BECK, C. (2018). Metodologias Ativas: conceito e aplicação. Andragogia Brasil. Disponível em: https://andragogiabrasil.com.br/metodologias-ativas/

BAZZO, W.A.; PEREIRA, L.T.V. Ensino de Engenharia: na busca do seu aprimoramento. Florianópolis: Editora da UFSC, 1997. Pág. 57

CECHELLA, Jéssica Cruz. Análise comparativa entre método tradicional $\mathbf{x}$ método sustentável de construção de um centro comunitário no Bairro Quarta Linha, Criciúma/SC. Trabalho de conclusão de curso para obtenção de bacharelado em Engenharia Ambiental - Universidade do Extremo Sul Catarinense, Santa Catarina, 2016. Disponível em: http://repositorio.unesc.net/handle/1/4169. Aceso em: 02 de maio de 2021.

FÓRUM DE PRÓ-REITORES DE EXTENSÃO DAS UNIVERSIDADES PÚBLICAS BRASILEIRAS. Política Nacional de Extensão Universitária. Manaus, 2012.

Disponível em: https://www.ufmg.br/proex/renex/images/documentos/Pol\%C3\%ADticaNacional-deExtens\%C3\%A3o-Universit\%C3\%A1ria-e-book.pdf. Acesso em abril de 2021

FUJIMOTO, A. et al. Educação na qualificação profissional da construção civil. Rev. Ciênc. Ext. v.8, n.3, p.294-302, 2012. EDUCAÇÃO NA QUALIFICAÇÃO PROFISSIONAL DA CONSTRUÇÃO CIVIL1

PUHL, Mário José. O conhecimento e o princípio da indissociabilidade entre ensino, pesquisa e extensão. Revista HISTEDBR On-line. Campinas, SP, v.16, n.69, 2016, p.222232.

SATTLER A. M. Edificações e comunidades sustentáveis. Universidade Federal do Rio Grande do Sul - Departamento de Engenharia Civil/NORIE. Porto Alegre, RS. Disponível em: http://www.usp.br/nutau/CD/sattler.pdf. Acesso em 01 de maio de 2021.

SARAIVA, J. L. Papel da Extensão Universitária na Formação de Estudantes e Professores. Brasília Médica, Brasília, v. 44, n. 3, p. 220-225, 2007

\title{
THE IMPORTANCE OF UNIVERSITY EXTESION IN THE FORMATION OF CIVIL ENGINEER
}

\begin{abstract}
In a perspective of the current scenario of undergraduate civil engineering students, it happens that most of the new students do not finish the course or are discouraged during the undergraduate period and this article aims to highlight university extension activities as a means of awakening interests and motivation for the course through humanization, education and sustainability. When it comes to sustainability, it is necessary to take a critical look at every procedure from the conception of the project to the completion of the construction, analyzing the needs of the residents, the location of the project, the climatic conditions and many other factors that influence the environment and daily life of the customer.
\end{abstract}

Keywords: Communities, University Extension, Humanization.engineering 
